Connotas. Revista de crítica y teoría literarias 


\begin{tabular}{|ll|}
\hline PQ6001 & Connotas. Revista de crítica y teoría literarias / \\
Director Fortino Corral Rodríguez.-Hermosillo, Sonora: \\
unIson. Departamento de Letras y Lingüística. \\
C2011. \\
V-: $23 \mathrm{~cm}$. \\
Semianual \\
Año VII, No. $12(2011)$ \\
ISSN: 1870-6630 \\
Incluye bibliografía. \\
1. Literatura española - Historia y crítica-Publicaciones \\
periódicas. 2. Literatura hispanoamericana - Publicaciones \\
periódicas. I. Corral Rodríguez, Fortino, dir.
\end{tabular}

CONNOTAS. REVISTA DE CRÍTICA Y TEORÍA LITERARIAS. Año VII, núm. 12, enero junio 2011, es una publicación semestral editada por la Universidad de Sonora, a través de la División de Humanidades y Bellas Artes, en el Departamento de Letras y Lingüística. Blvd. Luis Encinas y Blvd. Rosales s/n, Col. Centro, C.P. 83000, Hermosillo Sonora; Tel. (662) 2592 136, (662) 2592 157, <www.uson.mx>, <http://www.connotas.uson.mx, connotas@capomo.uson.mx>. Editor responsable: Rosario Fortino Corral Rodríguez. Reservas de Derechos al Uso Exclusivo núm. 04-2006-020714184900-102. ISSN: 1870 6630; ambos otorgados por el Instituto Nacional del Derecho de Autor. Licitud de Título núm. 13434 y de Contenido núm. 11007, otorgados por la Comisión Calificadora de Publicaciones y Revistas Ilustradas de la Secretaría de Gobernación. Impresa en Impresos RM S.A. de C.V., Privada Miguel Alemán no. 17, col. San Benito, Hermosillo, Sonora, México. Tel. 2 100212, e-mail impresosrm@gmail.com. Este número se terminó de imprimir el 5 de octubre de 2011 con un tiraje de 300 ejemplares. Las opiniones expresadas por los autores no necesariamente reflejan la postura del editor de la publicación.

Se autoriza la reproducción total o parcial de los contenidos de la presente publicación, siempre y cuando se acredite adecuadamente el origen de los mismos.

Este número se publicó con apoyo del Programa Integral de Fortalecimiento Institucional

Datos de contacto para la publicación: División de Humanidades y Bellas Artes, Departamento de Letras y Lingüística; Apartado Postal 793, Col. Centro, C.P. 83000, Hermosillo, Sonora, México. Tels.: (662) 259-21-87, Tel-fax 212-55-29. Correo electrónico: connotas@capomo.uson.mx Página web: http://www.connotas.uson.mx 


\section{Connotas. Revista de crítica y teoría literarias}

Año VII / Núm. 12 / Enero-junio 2011

COMPILAdOR DE ESTE NÚMERO

César Avilés Icedo

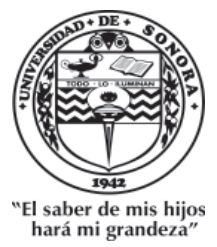

UNIVERSIDAD DE SONORA 


\section{UNIVERSIDAD DE SONORA}

RECTOR

Heriberto Grijalva Monteverde

VicerReCTORA

Arminda Guadalupe García de León Peñúñuri

Secretario General Académico

Enrique Fernando Velázquez Contreras

División de Humanidades y Bellas Artes

María Rita Plancarte Martínez

DePARTAMENTO DE LETRAS Y LINGÜÍSTICA

Martha Martínez Figueroa

COMItÉ EDITORIAL INTERNO

César Avilés Icedo

Rosa María Burrola Encinas

Fortino Corral Rodríguez

Leticia Martínez Figueroa

Jesús Abad Navarro Gálvez

Gabriel Osuna Osuna

María Rita Plancarte Martínez

DiRECTOR

Fortino Corral Rodríguez

Giuseppe Bellini

Universidad de Milán

Luis Beltrán Almería

Universidad de Zaragoza

Helena Beristáin

Universidad Nacional Autónoma de México

Raúl Bueno-Chávez

Dartmouth College

Evodio Escalante

Universidad Autónoma Metropolitana

Beatriz González-Stephan

Rice University

Aníbal González Pérez

Yale University

Aurelio González Pérez

El Colegio de México

Yvette Jiménez de Báez

El Colegio de México

Nelson Osorio Tejeda

Universidad de Santiago de Chile

\section{CONSEJO INTERNACIONAL}

Carlos Pacheco

Universidad Simón Bolivar

Rafael Olea Franco

El Colegio de México

Joan Oleza Simó

Universidad de Valencia

Julio Ortega

Brown University

Luz Aurora Pimentel

Universidad Nacional Autónoma de México

Susana Reisz

The City University of New York

José Carlos Rovira

Universidad de Alicante

Charles Tatum

The University of Arizona

Jorge Urrutia

Universidad Carlos III de Madrid

Emil Volek

Arizona State University 


\section{Índice}

\section{Artículos}

La ciudad fronteriza de Luis Humberto Crosthwaite en Estrella de la calle sexta e Instrucciones para cruzar la frontera

Martín Torres SAUChetT . . . . . . . . . . . . . 9

Artífices y simuladores: el influjo de los medios masivos y la cultura popular en la literatura latinoamericana del siglo XX Amalia Franco Castaño . . . . . . . . . . . . . . . . . 27

“Teoría del túnel”: El pre-texto de Rayuela Margarita Díaz de León Ibarra . . . . . . . . . . . . . . 45

Metaficción hispanoamericana y crisis de la representación literaria del sujeto

Jesús Eduardo Oliva Abarca . . . . . . . . . . . . 61

Los refranes y los poemínimos: análisis de una relación intertextual

IsAbelle Pouzet . . . . . . . . . . . . . . . . . . . . . . . . 79

\section{Notas}

La ciudad como categoría estética e ideológica en Cartas de relación de Hernán Cortés y Grandeza mexicana de Bernardo de Balbuena Jesús Abad Navarro Gálvez . . . . . . . . . . . . . . . . . 99 
Hacia una hermenéutica estridentista: de la crítica romántica a la crítica de vanguardia

Alberto Rodríguez González . . . . . . . . . . . . . . . . 111

Casas de encantamiento y El espía del aire, de Ignacio Solares: la reflexión de la escritura

Alejandra Sánchez Aguilar . . . . . . . . . . . . . . . . . . 123

\section{Reseñas}

Gilberto Giménez. Estudios sobre la cultura y las identidades sociales. México: Conaculta/ITESO, 2007

Ana Lourdes Álvarez Romero . . . . . . . . . . . . . . . . . . . 135

Angélica Tornero. El mal en la narrativa de Inés Arredondo. México: Casa Juan Pablos/Universidad Autónoma del Estado de Morelos, 2008

Griselda Córdova Romero . . . . . . . . . . . . . . . . . . . . . . . 141

Guadalupe Fernández Ariza, coord. Literatura hispanoamericana del siglo XX. Historia y maravilla. España: Universidad de Málaga, 2006

Mayra Alejandra Borbón Espinoza . . . . . . . . . . . . . . 147

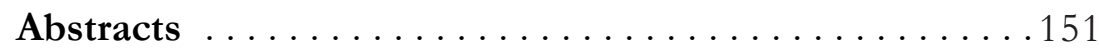

Résumés ... . . . . . . . . . . . . . . . . . . . . 157

Normas editoriales ..................... 163 


\title{
Casas de encantamiento y El espia del aire, de Ignacio Solares: la reflexión de la escritura
}

\author{
Alejandra Sánchez Aguilar*
}

\section{Resumen:}

Como resultado del cambio en la creación ficcional, el oficio del escritor, del crítico, del teórico y del lector se entrecruzan en la actividad literaria conformando una nueva veta dentro de la literatura moderna, que se dispone esencialmente como un cuestionamiento de sí misma, como una autocrítica de la creación. Este trabajo pretende, a partir del acercamiento a dos obras de Ignacio Solares: Casas de encantamiento (1987) y El espia del aire (2001), meditar sobre esta la literatura que discurre sobre las posibilidades de la ficción, y cuya tematización central es su propio ser literario. La reflexión teórica ya no se sitúa fuera de la obra, sino en su interior; es decir, subyace en el texto poético, unas veces explícita, otras implícita, y es susceptible de una reconstrucción teórica.

Palabras clave:

Reflexión de la escritura, intertextualidad, autocrítica, teoría en la literatura, Solares.

Crítica, teoría de la literatura, lectura y escritura literaria son discursos que transitan por caminos cercanos, pero que en primera instancia pueden ser asumidos como resultado de procesos escriturales y de pensamiento diferenciados. Sin embargo, cuando se

\footnotetext{
* Universidad Autónoma Metropolitana-México.
} 
pretende reflexionar en torno a la literatura moderna ${ }^{1}$ se hace necesario considerar el replanteamiento de estos discursos, sobre todo cuando la ficción les abre un espacio. Como resultado del cambio en la creación ficcional, el oficio del escritor, del crítico, del teórico y del lector se entrecruzan en la actividad literaria conformando un nuevo ser de la literatura, que se dispone esencialmente como un cuestionamiento de sí mismo, como una autocrítica de la creación. La literatura suspende por un momento la fantasía para convertirse ella misma en la aventura de su propio ser y hacer. La narrativa moderna $^{2}$ trata, pues, sobre el mundo que mejor conoce, el propio. En este espacio, obras narrativas como Casas de encantamiento (1987) y El espia del aire (2001), ambas de Ignacio Solares, encuentran un marco de referencia, en tanto que se disponen como novelas que extienden sus límites ficcionales y, por ende, genéricos, pues abren espacio al discurso crítico y teórico, y con ello dan paso a la reflexión que las vincula con formas como el ensayo. Lo cierto es que se colocan, más allá de la fabulación, en otro ámbito discursivo, por ejemplo el de la reflexión, para llevar a cabo una meditación de su propio ser.

${ }^{1}$ Parto entonces de la ficción moderna y específicamente de una veta que tiene que ver con la autorreflexión y el autocuestionamiento; la misma a la que se refiere Michel Foucault en su ensayo “¿Qué es un autor?,” en el que señala que la escritura de hoy "se ha liberado del tema de la expresión: y no se refiere más que a sí misma." El discurso literario se instaura como demasiado consciente de sí y de su proceso. "La escritura -agrega Foucault- se despliega como un juego que va infaliblemente más allá de sus reglas." (333)

${ }^{2}$ Para Hans-Georg Gadamer, el juego es el proceso que mejor expresa el modo de ser del arte y la literatura modernas, manifestado bajo los rasgos de la autonomía, el automovimiento, la repetición y la autorepresentación. En la literatura de hoy, apunta, "el verdadero sujeto del juego no es el jugador sino el juego mismo. Es éste el que mantiene hechizado al jugador, el que le enreda en el juego y le mantiene en él" ("La ontología” 149). El filósofo ve el origen de esto en la Primera y Segunda Guerra Mundial. La posguerra marca una ruptura y un redescubrimiento en el arte occidental; la desintegración trae como resultado la creación de manifestaciones artísticas más conscientes y más intensas (96-99). 
Dentro de este marco, a decir de Norma Angélica Cuevas Velasco, la metaficción, ${ }^{3}$ la escritura fragmentaria, la estética especular ${ }^{4}$ y la intertextualidad ${ }^{5}$ constituyen los procedimientos propios que estos textos emplean para conformar una teoría en la literatura. Más claramente, la investigadora propone la posibilidad de emplearlos como instrumentos descriptivos "mediante los cuales es posible construir y transmitir (comunicar) conocimiento por vía del efecto poético" (147).

Dicho de otro modo, esta narrativa puede ser objeto de una reconstrucción teórica, en el sentido en que en ella subyace una serie de razonamientos sobre la práctica de la escritura y un cuestionamiento esencial sobre las posibilidades que puede tener la literatura. Es tarea del crítico y del lector describir y entresacar esa teoría que es producto de una reflexión encarnada en el texto poético.

Partiendo de esto, Casas de encantamiento y El espía del aire forman parte de esta narrativa. Explícita e implícitamente, la reflexión se presenta en ambas para su posible develamiento. Más allá de su dimensión "fantástica" e "histórica," y de la aventura que plantean, que en sí misma ya versa sobre la actividad escritural, retornan al problema del ser ficcional.

Casas de encantamiento es publicada en 1987 y su argumento puede resumirse en lo siguiente: ubicada en los años ochenta, la historia del protagonista, Javier Lezama, es narrada por su amigo Edgardo.

3 "Literatura autorreflexiva, autoconsciente, autorrepresentacional, narcisista, todos ellos son términos que designan a la narrativa metaficcional, aquella que versa sobre sí misma, ficcionalizando su proceso de producción y de recepción al elaborar su propio/ metatexto que coloca en la escena textual su quehacer díctico y problematiza su status como ficción en las alteridades realidad/ficción y escritura/lectura que la hacen posible." (Gaspar 14)

${ }^{4}$ El relato especular es resultado de un myse en abyme, definido por Lucien Dallenbach como "todo espejo interno en que se refleje el conjunto del relato por reduplicación simple, repetida o espaciosa.” (59)

${ }^{5}$ La intertextualidad es "una relación de co-presencia entre dos o más textos, es decir, eidéticamente y frecuentemente, como la presencia efectiva de un texto en otro." (Genette 10) 
Mientras éste lee, el relato es escuchado, seguido y comentado por el profesor, dueño de la pensión donde Javier había vivido hasta su muerte. Aparentemente después de que es atropellado por un coche, Edgardo y el profesor recogen su diario íntimo y una serie de manuscritos pertenecientes a Luis Enrique Bautista. Este último -se sabe por lo escrito por Javier- se lanzó desde un piso alto del Edificio Nuevo León en los primeros días de 1985. Junto al diario, un cuento titulado "La ciudad" (1975) es encontrado entre los manuscritos y presentado como probable obra de Luis Enrique. Todos estos discursos conforman el rompecabezas de la escritura que da lugar a la obra.

La vida de Javier transcurre entre su obsesión por Luis Enrique y sus visitas a la Hemeroteca Nacional; su único interés es el año 1945. En una de esas ocasiones -motivado por la escritura de un reportaje- visita el cine Olimpia y en él encuentra la cartera de Margarita Vélez, una muchacha que vivió en 1945. Se obsesiona por ella y decide regresar a aquel lugar para su encuentro. En la hemeroteca sufrirá una serie de "entrevisiones" que lo llevan al año de 1945. Se produce una trasgresión temporal, lo que Edgardo nombra como la "maroma del tiempo:" Javier está en la noche en que Margarita perdió su credencial. Establece una relación con ella, vive el romance y en el culmen de la relación sexual regresa otra vez a la realidad. Unos meses después se produce el accidente que le provoca la muerte.

Por su parte, El espía del aire, publicada en 2001, tiene como protagonista a un joven de veinte años que narra sus vivencias de juventud, y en ellas recrea la vida literaria de los años sesenta. Su historia se resume en la búsqueda de la escritura perfecta que pretende alcanzar a través de la práctica automatizada de ésta. Al investigar para un reportaje sobre el cine Olimpia, el narrador encuentra una vieja credencial de 1945 y se enamora de la mujer que aparece en la fotografía: Margarita Vélez. Para conocerla tiene que regresar a ese año y únicamente lo logra a través de la escritura literaria: la trasgresión temporal y espacial se da cuando el personaje escribe. 
La reflexión acerca de la condición de la literatura, y la manera particular en que Solares propone el hacer de ésta, tiene lugar primeramente en su conformación intertextual. Ambas novelas pueden ser tomadas como una unidad discursiva, en tanto que comparten mucho el discurso que las conforma. La duplicación es tal que podríamos acercarnos a El espía del aire como a una reescritura de Casas de encantamiento, o al menos asumir aquélla como otra posibilidad de ésta. Sus protagonistas experimentan mucho de la misma historia y de sus circunstancias de vida. Una de éstas es precisamente la historia de amor con Margarita. En Casas de encantamiento, Edgardo lee en el diario de Javier lo siguiente:

La besó en el cuello y buscó los senos; desabrochó un botón que encontró en el camino. Ella puso resistencia un instante pero luego cedió y su respiración empezó a alterarse. Le quitó la blusa. En la penumbra del cine había adivinado sus ojos y ahora igual adivinaba su cuerpo: lo reconocía más que descubrirlo. Como si lo inventara él mismo. (151)

Por otro parte, en El espía nuestro protagonista anónimo, al que la crítica ha identificado como el alter ego del escritor, expresa:

La seguí besando en el cuello y desabroché un botón que encontré en el camino. Ella continuó oponiendo resistencia un instante, pero luego cedió y su respiración empezó a alterarse. Le quité la blusa. En la credencial había adivinado sus ojos, el fondo de sus ojos, y ahora igual adivinaba su cuerpo: lo reconocía más que descubrirlo. Como si lo inventara yo mismo. (96)

Como se puede interpretar, dentro de El espía del aire está presente Casas de encantamiento; la segunda novela se erige como el "texto-génesis," por ser antecedente y el origen del discurso que despliega El espía. Debe entenderse que la meditación acerca de la escritura es además expresada en la estructura de la obra, en la propuesta formal. No obstante, como bien apunta Cuevas, "en el caso en que el comentario es implícito, hay mayor dificultad para 
comprender la reflexión teórica o la propuesta conceptual; a pesar de esto, su eficacia no se pone en duda" (151).

A la repetición textual y circunstancial y, por supuesto, a la trama compartida se suma la tematización y el discurrir sobre la actividad escritural ${ }^{6}$ en general, el papel del la ficción y la otra realidad que ésta dispone, así como las figuras del escritor y del lector. Particularmente, las palabras iniciales de El espia del aire dan cuenta del acento y temática que predomina en ambas obras: la literatura y las prácticas derivadas de ésta: "Como si el simple acto de escribir pudiera hacer girar al revés las agujas del tiempo. [...] La literatura era gnosis, revelación, desdén de una realidad limitante y trivial, previa a la revolución (que parecía inminente). Los libros, voraces circulaban entre mi pequeño grupo de amigos universitarios" (11).

Si bien la materia acerca del escribir y el leer son parte de los tópicos de la historia de la literatura universal, ciertas especificidades sobre la meditación sobre el ser ficcional pueden ser situadas en un momento histórico particular. Asimismo, dentro del marco de la literatura mexicana y latinoamericana, esta clase de narrativa agrupa a ciertos escritores que se distinguen por incorporar la reflexión teórica y el comentario crítico dentro de su obra:

Jorge Luis Borges, Adolfo Bioy Casares, Julio Cortázar, Ernesto Sábato, Alejo Carpentier, José Lezama Lima, Guillermo Cabrera Infante, Mario Vargas Llosa, Reinaldo Arenas, Ricardo Piglia, Alfonso Reyes, Jorge Cuesta, Octavio Paz, Josefina Vincens, Salvador Elizondo, Julieta Campos, Juan García Ponce, Juan Vicente Melo, Vicente Leñero, José Emilio Pacheco, Carlos Fuentes, Ignacio Solares y Gonzalo Celorio...

${ }^{6} \mathrm{El}$ problema de la escritura y la lectura, ya sea formalmente o tematizado al interior de la narrativa, es una constante a lo largo de toda la producción de Ignacio Solares. Personajes que escriben y leen, libros y diarios que están siendo escritos y leídos en el momento de la enunciación son rasgos propios de la escritura del autor. El sitio (1998), La invasión (2005) y Anoche en la oscuridad (manuscrito) son sólo algunas de sus obras que contienen esta problemática. 
Algunas de las producciones artísticas de estos autores han recibido entre otros posibles calificativos el de obras experimentales, nuevas novelas o, más tarde, metaliteraturas o metaficciones. $^{7}$ (Cuevas 141)

En el caso particular de la narrativa de Ignacio Solares, además de la reflexión implícita presente en la construcción discursiva y formal, en el argumento se encuentra presente también la expresión de una preocupación acerca de las posibilidades y el poder de la escritura literaria. Sus protagonistas logran quebrantar la temporalidad y espacialidad de la realidad configurada en la ficción. A partir del hallazgo de la credencial perdida de Margarita Vélez, sufrirán una obsesión y, más tarde, un enamoramiento por aquella mujer misteriosa que los llevará a burlar la realidad en que se encuentran confinados.

El salto tendrá lugar en Casas de encantamiento a partir del poder imaginativo de su protagonista, el cual, no hay que dejar de mencionar, se halla escribiendo en la hemeroteca. Sin embargo, tanto Edgardo como el profesor atribuyen esta circunstancia insólita al estado de ayuno que mantenía Javier. Por su parte, en El espía no queda duda de que es la escritura, descrita como otra forma de ensoñación, la que logra burlar el tiempo. Este viaje espaciotemporal conforma la aventura que, en los dos textos, convive con la propuesta conceptual sobre la palabra creadora y su recepción particular. Tanto Javier como el personaje anónimo en El espía quebrantan las circunstancias conformadas en la ficción y determinan las nuevas condiciones para esa realidad.

\footnotetext{
${ }^{7}$ En su texto Escritura y Metaficción, Catalina Gaspar ofrece un corpus para referirse a los autores latinoamericanos cuya obra considera posee estas características: Juan Carlos Onetti, Jorge Luis Borges, Guillermo Menesses, Julio Cortázar, Gabriel García Márquez, Mario Vargas Llosa, José Donoso, Salvador Garmendia, Luis Britto García, Antonieta Madrid, Severo Sarduy, Lezama Lima, Fernando del Paso, Augusto Roa Bastos, Marco Denevi, Manuel Puig, Bryce Echenique, Carlos Noguera y Salvador Elizondo" (19). En dicho texto de Gaspar, como puede verse, hay autores que coinciden con los mencionados por Norma Angélica Cuevas.
} 
Cabe detenerse en la manera en que Javier realiza la transición, pues la experiencia es resultado de una especie de viaje astral detonado por la falta de alimento. Gracias a este estado de ayuno, Javier se instala en una nueva dimensión donde el intersticio entre un tiempo y otro se manifiesta a través de un mundo de cera. Sin embargo, la escritura nunca deja de aparecer, pues todo esto ha sido escrito por el protagonista. Lo anterior es relevante si se toma en cuenta que dentro de la narrativa de Ignacio Solares la escritura es equiparada con los estados de vigilia, alucinación y, en general, con los estados oníricos. No obstante, en El espía es sin duda la escritura la que motiva esta alteración espaciotemporal:

Escribía esperando vagamente que en esa falsa concentración, que era a la vez voluntad de distracción -y en aquel horrendo lugar, apestoso a orines-, se abriera de nuevo el hueco inicial, por donde se había colado a esta realidad la estrella de evasivas puntas de una credencial emparedada por el tiempo. Acaso la constelación brotaría de esa aura todavía presente en el Olimpia, se sedimentaría en una zona más allá o más acá del lenguaje, dibujaría sus radios transparentes, la fina huella del rostro fotografiado hacía veinte años. La escritura valía como una de las hebras -la hebra principal, sin lugar a dudas- que hubiera querido atar a las otras hebras mentales para alcanzar por fin una comprensión, algo que acaso pudiera tener imagen y nombre propio. (44)

Dentro de la ficción de Ignacio Solares, las posibilidades de la existencia y de crecimiento de la condición humana se generan muchas veces a través de la creación de universos alternos: los sueños, las alucinaciones, las evasiones fantasiosas y los sucesos fantásticos. Al lado de estos, se encuentra también la escritura cuyos procedimientos conducen a la profundidad que se permite experimentar a través de aquellos estados. Todas estas experiencias permanecen separadas del mundo de lo real por una delgada línea que se transgrede por momentos, lo cual permite dirigirse a ese más allá que se ampara en nuestro lado irracional. El propio Solares dice: 
"quizá las cosas no finalicen en el punto en que nuestros hábitos mentales presuponen" (Cartas 76).

Así, estas novelas se refieren, además de a sí mismas y a su condición literaria, a "otra cosa." Esta otra cosa es, como he dicho, la aventura que corre paralelamente a la reflexión: la maroma en el tiempo, tal como la nombra Edgardo. El suceso permitirá a los protagonistas imponer sus propias condiciones a la ficción. Por todo lo anterior, es viable asumir que esta clase de narración se propone, por un lado, como forma de pensamiento y razonamiento y, por otro, como forma de acción y de fabulación. El argumento ya es parte de la reflexión, pues son la escritura y la fantasía las que permiten el salto que une a Margarita con los protagonistas. Asimismo, como se ha dicho, la escritura, al lado de los sueños, las alucinaciones y la imaginación, es concebida como un estado de enajenación que por su naturaleza de alteración, locura y deformación permite acceder a una tercera frontera. En esta nueva realidad se puede vivir mil veces más lo que ya se ha vivido, sin la culpa causada por los relojes, sin la manía de los minutos y el pasado mañana.

Por otro lado, los procedimientos metaficcionales y de intertextualidad son el hacer específico que estas novelas emplean para exponer su discurrimiento sobre el ser de la literatura. El quebrantar los límites de la realidad configurada por la ficción, la exigencia de un lector participativo que se involucre en el hacer y la obra que subraya su naturaleza ficcional son, específicamente, los medios metaficcionales utilizados. Estas formas favorecen a la reflexión que, considero, gira sobre el problema de los límites entre la ficción y la realidad y, en particular, sobre el intersticio que surge de la transgresión de estos límites y el papel que juega esa otra realidad que se construye. La escritura y la lectura son los procesos que conforman dicho intersticio y que permiten vislumbrar una nueva realidad.

Casas de encantamiento y El espía del aire son obras en las que se puede reconocer claramente los rasgos de la metaficción. "Su empeño por involucrar al lector en la (re) escritura de la obra, el incluir elementos de la realidad histórica, la alusión o la cita de otros textos [...] la participación ficcional del autor para desmitificar la idea 
de su dominio sobre el texto" (Cuevas 142). A lo que hay que agregar uno de los temas preferidos de la escritura de condición metaficcional: la muerte del autor. Todos estos rasgos son propios de una narración autorreflexiva y se encuentran presentes en ambas novelas, como los procedimientos específicos que disponen la meditación y que a su vez permiten entresacar, describir y organizar el comentario literario que contienen. En el caso de El espía del aire, está presente la reescritura de la transgresión espaciotemporal y la historia perteneciente a Casas de encantamiento, la reconstrucción histórica de los años sesenta y cuarenta, numerosas alusiones al mundo intelectual de aquellos años, la participación del autor en la historia relatada de Margarita Vélez y varias referencias a textos de la literatura universal. Por su lado, en Casas de encantamiento está presente la reescritura de algunos fragmentos de otras obras del autor, como Anónimo y Serafín, la realidad histórica de los años ochenta y cuarenta, la muerte del autor y varias referencias a textos de la literatura universal.

Casas de encantamiento y El espía del aire transitan por la literatura autorreflexiva; específicamente, el procedimiento que cobra mayor relevancia es la maroma de tiempo que experimentan sus protagonistas, la cual es en sí misma la propuesta conceptual, es decir, la reflexión teórica que versa sobre la configuración de un intersticio que permite el surgimiento de una nueva realidad. La subversión del tiempo y la realidad fusiona el acto de la enunciación con el enunciado, escribir es hacer, y en este sentido escribir es romper los límites de la realidad y abrir una tercera frontera dispuesta entre lo escrito y lo real. El procedimiento hace del acto escritural un ser, que se realiza mientras se lee y es el lector el que culmina el proceso en la praxis estética, no en el sentido en que la obra es incompleta, sino más bien en su labor interpretativa.

En El espía del aire, escribir es hacer. La escritura produce el movimiento de la trama, y la trama misma se convierte en el ser de la escritura. En relación con Casas de encantamiento, El espía reflexiona sobre el infinito juego del decir, que nunca acaba, que siempre continúa, pues finalmente termina por ser una segunda versión de la primera historia. El hecho es que en ambas obras el comentario 
pesa, el decir sobre la escritura sobresale y ya no se sitúa como efecto posterior a la terminación de la obra, sino que se produce en el momento de la actividad escritural. Lo que correspondería al teórico o al crítico de la literatura es vertido ahora en la obra que se vuelca sobre sí misma. La teoría de la literatura y la crítica de la literatu$r a$, que antes mediaban entre el lector y la escritura, ahora se disponen en esta última. La aproximación que sufre el oficio del crítico y el escritor parece lógica cuando se habla de escritores que son críticos y de críticos que son escritores. La tentación de ambos por desplegar sus afinidades los conduce a desembocar en formas discursivas que se aproximan: una novela que parece acercarse, por ejemplo, al ensayo, pues no se limita a contar una aventura, sino que además discute sobre ella.

Lo más importante para que una obra pueda ser considerada autocrítica y reflexiva es que su referente interno predomine sobre el referente externo. Será este "referente interno el que cobre mayor resonancia en la recepción de la obra: no serán los personajes, el narrador o la trama las que recuerde el lector, sino el tratado del concepto, la noción alrededor de la cual fueron surgiendo personajes, narradores, tramas" (Cuevas 146). Casas de encantamiento y El espia del aire son obras en las que la noción alrededor de la cual surge la trama es el intersticio que abre la escritura, como centro que mueve los hilos de ambas narraciones, y en las que el escritor es concebido como un espía del aire que tiene la capacidad de traducir el lenguaje secreto con que nos enamoran las cosas vistas, leídas o escuchadas. Es el narrador que escribe la aventura el que permite la realización de la trama; sin embargo, insisto, la aventura no se nulifica. La aventura, por el contrario, es motivada por la actividad escritural.

La intertextualidad, la metaficción y la especulación son los procedimientos que permiten hacer la identificación de la reflexión acerca de la literatura, presente en la narrativa de Ignacio Solares. En Casas de encantamiento y El espía del aire, el referente o los referentes son el acto de escribir, el discurso literario (el diario, la crónica, el cuento), la figura del lector y del escritor y el ser de la ficción en sí mismo. Más específicamente, me interesa lo que se dice de esos 
referentes. En ese decir y en esa reflexión fundamentan ambas novelas su "carácter de búsqueda," escritura que se cuestiona, más que responderse, las posibilidades de la literatura. El espía del aire, en tanto que retoma las raíces de Casas de encantamiento, es testimonio de ese ineludible movimiento infinito del decir de la literatura moderna, del no acabar porque la reflexión no se agota.

\section{Bibliografía}

Cuevas, Norma Angélica. El espacio poético en la narrativa. De los aportes de Maurice Blanchot a la teoría literaria y de algunas afinidades con la escritura de Salvador Elizondo. México: Casa Juan Pablos/UAm Iztapalapa, 2006.

Dallenbach, Lucien. El relato especular. Tr. Ramón Buenaventura Sánchez Paños. Madrid: Visor, 1991.

Foucault, Michel. “¿Qué es un autor?” Entre filosofía y literatura. Tr., intr. y ed. de Miguel Morey. Barcelona: Paidós, 2003.

Gadamer, Hans-Georg Gadamer. Poema y diálogo. tr Daniel Najmía. Barcelona: Gedisa, 1999.

"La Ontología de la obra de arte y su significado hermenéutico." Verdady Método. Tomo II. Tr. Manuel Olasagasti. Salamanca: Editorial Sígueme, 1994

Gaspar, Catalina. Escritura y metaficción. Caracas: La Casa Bello, 1995. Genette, Gérard. Palimpsestos. La literatura en segundo grado. Tr. Celia Fernández Prieto. Madrid: Taurus, 1989.

Solares, Ignacio. Anónimo. México: SEp, 1979.

- Serafín. México: Diana, 1980.

—. Casas de encantamiento. México: Plaza \& Janés, 1987.

- El sitio. México: Alfaguara, 1998.

—. El espía del aire. México: Alfaguara, 2001.

- La invasión. México: Alfaguara, 2005.

- Anoche en la oscuridad. México: Manuscrito, 2006.

- Cartas a un joven sin Dios. México: Alfaguara, 2008. 